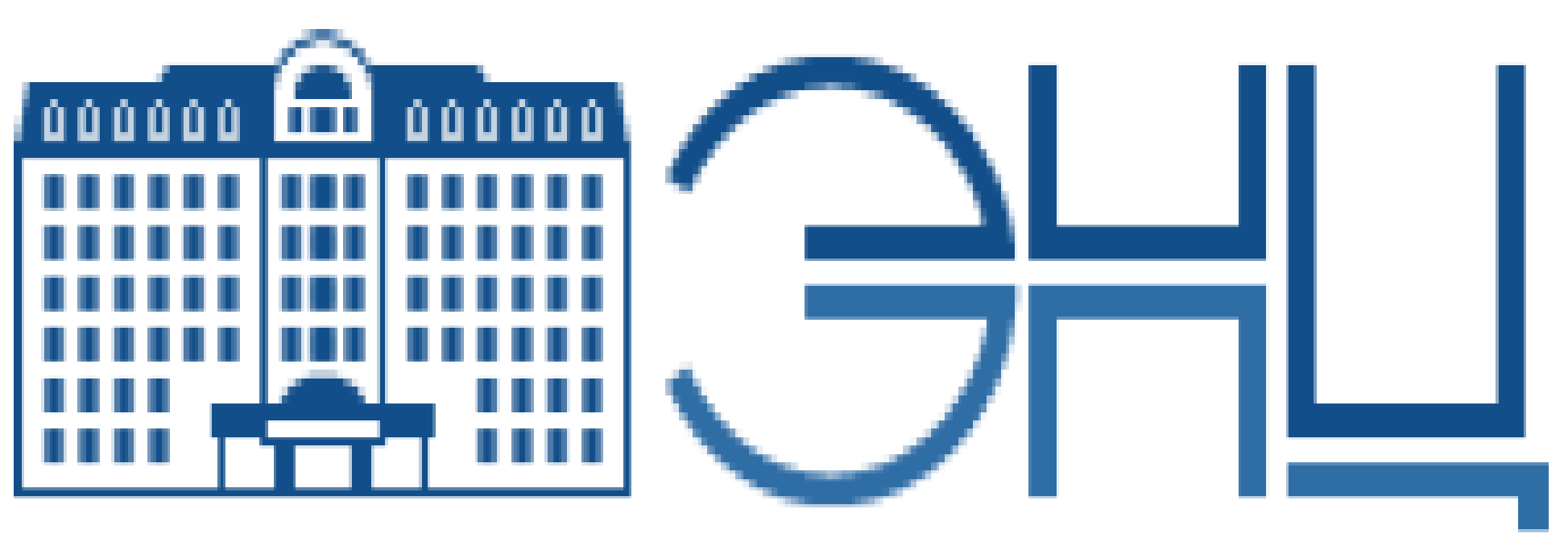

ЭНДОКРИНОЛОГИЧЕСКИЙ НАУЧНЫЙ ЦЕНТР

Department of

Neuroendocrinology

and Bone Diseases

\section{Metabolic changes in vitamin D deficiency}

\author{
Alexandra Petrushkina ${ }^{2}$, Ekaterina Pigarova ${ }^{1}$, \\ Tatiana Tarasova ${ }^{1}$, Liudmila Rozhinskaya ${ }^{1}$ \\ 1 Endocrinology Research Centre, Moscow, Russia \\ 2 Lomonosov Moscow State University, Moscow, Russia
}

The improvement of vitamin D status is necessary to overcome an impaired calcium-phosphorus metabolism and disturbances in other tissues functioning; safety of medical intervention should include analysis of metabolic changes.

\title{
Methods
}

24 apparently healthy volunteers $24,9 \pm 2$ y.o. were included in the study: Group $1(11 / 24)$ with blood serum levels of $25(\mathrm{OH}) \mathrm{D}$ $<10 \mathrm{ng} / \mathrm{mL}$ and Group $2(13 / 24)$ with $25(\mathrm{OH})$ D levels $10-20 \mathrm{ng} / \mathrm{mL}$.

Assessments were made at baseline; 3 hours; 3,7 and 28 days after intake of $200000 \mathrm{IU}$ of cholecalciferol oil solution.

\begin{tabular}{|c|c|}
\hline \multicolumn{2}{|c|}{$\begin{array}{c}\text { 25(OH)D (ng/mL) } \\
M \pm S D(\text { Min-Max) }\end{array}$} \\
\hline Group $1(n=11)$ & Group $2(n=13)$ \\
\hline $7,3 \pm 2,1(4,0-9,9)$ & $15,1 \pm 3,0(10,7-19,5)$ \\
\hline
\end{tabular}

\section{Results}

At baseline we observed significantly higher mean level of PTH $(63,0 \pm 17,2$ vs. $35,3 \pm 10,2 ; p<0,01)$ with elevation above the upper level of normal range (ULN) in 36,4\% in Group 1 whereas in Group 2 levels met normal range in all individuals. Urine calcium/creatinine ratio (CCR), $\mathrm{mmol} / \mathrm{mmol} \mathrm{M} \pm \mathrm{SD}$ (Min-Max): Group $1-0,25 \pm 0,13(0,12-$ $0,58)$, Group $2-0,31 \pm 0,21(0,03-0,71)$; values were less than lower level of normal range $(0,1)$ in $15,4 \%$ in Group 2. Blood serum $\mathrm{Ca}_{\text {tot }}, \mathrm{Ca}_{\text {ion }}$ and $\mathrm{P}$ levels were not different between the groups and were within the normal range.

By 28th day $41,6 \%$ and $87,5 \%$ from all participants achieved $25(\mathrm{OH}) \mathrm{D}$ blood serum level $>30 \mathrm{ng} / \mathrm{mL}$ and $>20 \mathrm{ng} / \mathrm{mL}$ respectively. By $3 d$ day we observed significant decrease of PTH level in Group 1 (by $27 \%, p<0,05$ ). There was no significant changes in CCR during follow-up period, but in one individual we observed an increase higher than ULN ( $\max C C R=0,89$ ) which was transient. We also observed one case of hypercalcemia ( $\max$ $\mathrm{Ca}_{\text {tot }}=2,65 \mathrm{mmol} / \mathrm{L}$ ) which wasn't associated with increase in $\mathrm{Ca}_{\text {ion }}$.

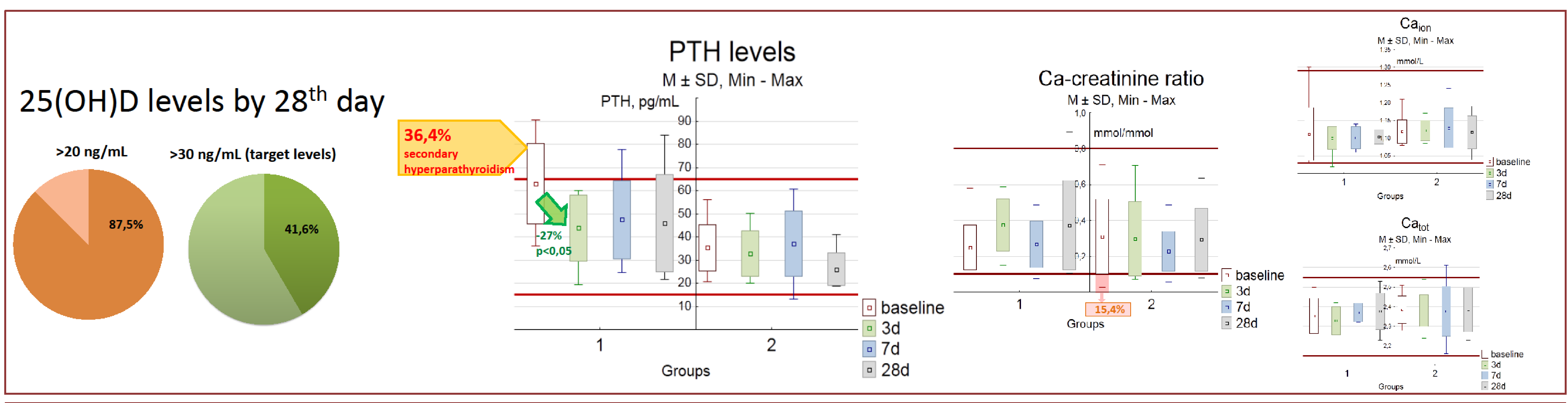

\section{Conclusion}

High-dose oral cholecalciferol treatment for vitamin D deficiency is efficient and safe in young patients regardless of severity of vitamin D deficiency. 